
internationales

vol. 20 - n² 2004

L'asile politique en Europe depuis l'entre-deux-guerres

\title{
Z. GUILMOTO Christophe et SANDRON Frédéric, Migration et développement
}

Yves Charbit

\section{(2) OpenEdition \\ 12 Journals}

Édition électronique

URL : https://journals.openedition.org/remi/4050

DOI : $10.4000 /$ remi.4050

ISSN : $1777-5418$

Éditeur

Université de Poitiers

Édition imprimée

Date de publication : 1 septembre 2004

Pagination : 201-202

ISBN : 2-911627-37-7

ISSN : 0765-0752

Référence électronique

Yves Charbit, «Z. GUILMOTO Christophe et SANDRON Frédéric, Migration et développement », Revue européenne des migrations internationales [En ligne], vol. 20 - n² | 2004, mis en ligne le 25 septembre 2008, consulté le 16 avril 2022. URL : http://journals.openedition.org/remi/4050 ; DOI : https://doi.org/ 10.4000/remi.4050

Ce document a été généré automatiquement le 16 avril 2022.

(c) Université de Poitiers 


\title{
Z. GUILMOTO Christophe et SANDRON Frédéric, Migration et développement
}

\author{
Yves Charbit
}

\section{RÉFÉRENCE}

Z. GUILMOTO Christophe et SANDRON Frédéric, Migration et développement, Les études de la Documentation Française, Paris, 2003, 142 p.

Guilmoto et Sandron publient un ouvrage qui s'inscrit dans la suite de leurs travaux sur l'analyse institutionnelle de la migration $(1999,2000)$, ouvrage important pour le public français parce qu'il analyse les migrations du point de vue des pays de départ, ce qui pose d'emblée la question des rapports entre migration et développement. D'autre part, les auteurs, qui ont une remarquable vision pluridisciplinaire, privilégient certes, en tant que démographes, la mesure des flux. Mais ils ont aussi le souci d'identifier des grands systèmes, géographique et rejoignant en cela les travaux de Gildas Simon ou Mary Kritz et en tant qu'économistes et socio-démographes, ils proposent aussi une typologie des profils migratoires qui intègre les dimensions socio-économique et démographiques. Guilmoto et Sandron apportent enfin une attention particulière à l'économie des migrations internationales. Ils repartent du modèle de Todaro, pour souligner les limites de l'analyse économique néo-classique appliquée à la migration, car l'ajustement de la mobilité à un marché fluide suppose des conditions à l'évidence manquantes : les barrières politiques s'opposent à la mobilité, les marchés, supposés permettre un ajustement libre de l'offre et la demande de travail sont quasi-inexistants. Dans les pays de départ, les marchés sont en réalité segmentés socialement ou ethniquement, tandis que dans les pays d'immigration, les embauches se font souvent par recommandation ou relation et la logique économique est fortement médiatisée par des facteurs socio-culturels. 
2 L'analyse économique débouche donc inévitablement sur la prise en compte de la dimension sociologique. Les auteurs font alors appel à des outils tels que les diasporas, les réseaux communautaires, les associations de migrants hautement qualifiés et le comportement de l'acteur individuel qu'est le migrant est beaucoup plus lisible et sa rationalité plus claire si l'on se situe au niveau « méso ». Guilmoto et Sandron montrent bien que tout repose sur la force d'un contrat moral avec sa communauté d'origine. $\mathrm{Ne}$ plus être reconnu socialement par celle-ci, et par exemple ne plus pouvoir accéder au marché matrimonial villageois après le retour reste suffisamment important en Inde pour que le migrant respecte les engagements pris : il a bénéficié d'un capital social qui est celui du groupe que le sien propre. Aussi « la force des liens faibles ", théorisée par Granoveter s'applique-t-elle bien à la migration internationale: elle renvoie à la logique des réseaux, qui s'imposent aux individus, même si leur contrôle sur eux paraissent ténus. Plus généralement, la migration s'inscrit beaucoup plus dans une perspective de minimisation des risques pour le groupe familial que de maximisation de revenus, la logique étant la même que pour l'exode rural: pour une famille paysanne, la migration interne permet de parer à la catastrophe des aléas climatiques grâce à la diversification des sources de revenus.

3 Tout au long de l'ouvrage, publié dans une collection qui allie contribution scientifique et objectifs pédagogiques, les auteurs proposent des typologies utiles : sur les profils migratoires (chapitre 3), sur les politiques migratoires tant internes qu'internationales (chapitre 6). Ils rassemblent des chiffres indispensables (sur les montants des transferts) et parfois peu connus (sur le prix à payer aux passeurs selon le pays de destination : jusqu'à 60000 US\$ pour un Chinois qui cherche à entrer clandestinement aux états-Unis, contre 300 US\$ s'il veut aller à Hong-Kong).

4 Le dernier chapitre est consacré à la question de la contribution de l'émigration au développement. L'importance des transferts officiels doit être majorée du « commerce à la valise ", impossible à évaluer. Leur impact économique est aussi indirect par les créations d'emplois que les dépenses réputées non productives (construction d'une maison par exemple) génèrent. Et si l'argent disponible permet de meilleurs soins ou une éducation plus poussée, alors il y a bel et bien contribution au développement. Reste la question des tensions inflationnistes que le pouvoir d'achat induit (notamment sur le foncier).

5 Le lecteur dispose désormais d'une indispensable entrée en matière d'un excellent niveau scientifique et d'une lisibilité parfaite, très complémentaire de deux autres publications de la Documentation Française sur les aspects démographiques et la relation avec les enjeux socio-démographiques du développement (éducation, santé, urbanisation, statut de la femme,etc.). 


\section{AUTEURS}

YVES CHARBIT

Popinter, Université Paris V 